\title{
Caracterização de Barra de Frutas Desidratadas com Granola
}

\author{
Karolline F. Siqueira \& Christiane A. Starling
}

A crescente demanda do consumidor por alimentos que apresentem qualidade nutricional e sensorial tem feito com que a indústria busque novas formas de apresentação das barras de cereais, muitas vezes, sem aporte nutricional. O objetivo deste trabalho foi caracterizar química e microbiologicamente uma barra a base de frutas desidratadas e granola, produto de um Edital de inovação. A barra apresentou conteúdo elevado de alguns micronutrientes e fonte de fibra alimentar, sendo uma alternativa para indivíduos com intolerância ao glúten, diabéticos e consumidores que buscam um produto diferenciado por sua qualidade sensorial e nutricional.

Palavras-chave: barra; frutas; qualidade.

The growing consumer demand for foods that have nutritional and sensory quality has made the industry look for new forms of presentation of cereal bars, often without nutritional support. The aim of this study was to characterize chemically and microbiologically a slash the base of dried fruit and granola, product of an innovation Notice. The bar presents a high content of some micronutrients and source of dietary fiber and is an alternative for individuals with gluten intolerance, diabetics and consumers who seek a differentiated product for their sensory and nutritional quality.

Keywords: bar; fruit; quality. 


\section{Introdução}

A crescente demanda do consumidor por alimentos que apresentem benefícios associados à saúde, coloca alguns alimentos e ingredientes na lista de preferência de um número cada vez maior de consumidores brasileiros, como a soja, a linhaça, castanhas, frutas secas, entre outros ${ }^{17}$.

À medida que aumenta a preferência dos consumidores pelos alimentos naturais, cresce o consumo de frutas secas e das barras de cereais. A tendência de consumir um produto mais nutritivo como substituto de doces e tortas tem feito que a indústria busque novas formas de apresentação das barras de cereais ${ }^{25}$.

A associação entre barra de cereais e alimentos saudáveis é uma tendência já documentada no setor de alimentos, o que tem beneficiado o mercado destes produtos. Muitos compostos encontrados nos alimentos são responsáveis por efeitos benéficos, observados em indivíduos que os consomem. Com o tempo, para as refeições cada vez mais curto e com uma tendência de comer uma variedade cada vez menor de alimentos, a variedade de nutrientes também diminui, e para que se tenha uma boa saúde, a dieta precisa ser bastante equilibrada ${ }^{25}$.

No início da década de 90, os principais consumidores de barras eram os esportistas. Atualmente, o consumo também é feito por pessoas não atletas e observase a produção de barras para segmentos de mercado específicos, como barras contendo vitaminas e minerais específicos para mulheres; barras formuladas visando à saúde da próstata do homem; barras para diabéticos, que estabilizam o nível de açúcar do sangue; barras sem glúten para portadores de doença celíaca e barras que auxiliam no funcionamento do intestino. Esses são alguns dos mais variados exemplos das novas barras produzidas para segmentos específicos ${ }^{17}$.

As barras de cereais apresentam formato retangular e tamanho pequeno, que com o passar dos anos, tem se modificado, passando de um produto "duro" e crocante para um produto "macio" e mastigável. Atualmente, também é oferecido coberto com chocolate ${ }^{17}$.

Alguns alimentos são formulados de forma a suprir algumas deficiências ou melhorar a absorção de nutrientes, e/ou alguma outra ação ao ponto de conseguirem um benefício fisiológico no indivíduo, promovendo a saúde e reduzindo o risco a certas doenças. O Brasil possui um número muito grande de frutas nativas de grande valor nutricional, com altos teores de vitaminas e minerais, sendo usadas pela população há séculos como uma forma de complementar a dieta diária. Frutas são alimentos frágeis e com alta perecibilidade, e a fim de conseguir conservar pelo maior tempo possível o fruto in natura a desidratação é um método bastante eficiente ${ }^{16}$.

O desenvolvimento de novos produtos pode auxiliar no aumento do consumo de cereais integrais e frutas desidratadas, resultando na melhoria de ingestão de fibra e de outros componentes saudáveis. Os benefícios destes alimentos contribuem positivamente para redução de doenças crônicas e conseqüentemente com redução dos efeitos induzidos por estas, contribuindo com a melhoria da qualidade de vida ${ }^{16}$.

A criação de novos produtos, modificação em suas formulações e complementação de produtos existentes, com frutas desidratadas torna-se necessário para garantir ao consumidor um produto que tenha algum diferencial em relação às barras de cereais já existentes no mercado. A dieta alimentar do consumidor, focada na preocupação de consumir alimentos mais saudáveis, tem impulsionado o mercado que cresce cerca de $20 \%$ ao ano, por exemplo, para as das barras de cereais. No cenário brasileiro, há crescimento significativo, principalmente, devido à tendência de consumo de alimentos saudáveis com alto teor de fibra e baixo teor de gordura ${ }^{17}$.

A divulgação da importância da fibra alimentar junto à recomendação do incremento de seu consumo têm levado a indústria de alimentos a desenvolver novos produtos e preparados dietéticos enriquecidos com fibra. Uma maior ingestão de fibra alimentar pode ocorrer por meio de alimentos de origem vegetal, natural e dos processados (barras de cereais, granola, frutas desidratadas, cereais matinais ${ }^{23}$.

O valor das fibras foi reconhecido há mais de duas décadas e o seu consumo está associado à integridade funcional do trato gastrointestinal. As indústrias de alimentos, aproveitando a oportunidade, colocaram no mercado vários produtos enriquecidos em fibras, visando atender à demanda crescente de indivíduos interessados em resgatar hábitos saudáveis, levando ao questionamento de como obter a quantidade diária de fibras recomendada por meio do consumo de alimentos naturais ${ }^{23}$. 
As fibras alimentares têm ocupado uma posição de destaque devido à ação benéfica desses nutrientes no organismo e à relação entre o seu consumo em quantidade adequada e a prevenção de doenças ${ }^{4}$.

No Brasil, o Ministério da Saúde, pela portaria $n^{\circ}$ 41, de 14 de janeiro de 1998, define fibras alimentares como: "Qualquer material comestível de origem vegetal que não seja hidrolisado pelas enzimas endógenas do trato digestivo humano, determinado segundo o método 985.29 da AOAC 15aed. 1990 (método enzimáticogravimétrico) ou edição mais atual ${ }^{5}$.

Analisando o hábito alimentar da população brasileira, verifica-se uma baixa ingestão de alimentos fontes de fibras, principalmente, nos grandes centros urbanos, onde a correria do dia a dia influencia de forma negativa no estilo de vida das pessoas, contribuindo para o maior consumo de produtos refinados, menor frequência de alimentos naturais na dieta e a substituição de refeições caseiras por lanches rápidos, na maioria das vezes gordurosos e desbalanceados ${ }^{16}$.

A relação entre o consumo de fibra alimentar e a incidência de enfermidades gastrointestinais tem sido demonstrada ${ }^{26}$.Na África, onde o consumo médio de até $150 \mathrm{~g}$ de fibra ao dia, a população não apresenta praticamente enfermidades como a constipação crônica, diverticulose e cólon irritável. Por outro lado, em países industrializados, com um consumo de fibra consideravelmente menor (aproximadamente $15 \mathrm{~g} / \mathrm{dia}$ ), apresentam um número muito alto dessas enfermidades, desencadeando o preocupante aumento da incidência e mortalidade pelo câncer colorretal ${ }^{16}$.

Frequentemente, as fibras das frutas possuem uma característica específica diferencial, que consiste na presença de quantidades significativas de compostos minoritários com elevada atividade biológica, tais como polifenóis e carotenoides ${ }^{23}$.

Dentre os alimentos ricos em fibras, também destaca-se a granola, que é um produto alimentar constituído por uma mistura de frutas secas, grãos de cereais e sementes oleaginosas, tais como o amendoim e castanha-do-pará Embora seja um alimento nutritivo, rico em fibras, carboidratos e lipídios, possui baixo teor de proteínas, apresentando-se como produto energético, e de sabor agradável ${ }^{22}$.

Para o consumidor, tais produtos significam opções variadas para as diversas necessidades, enquanto para a indústria alimentícia representam uma oportunidade de colocarem no mercado produtos inovadores.

Assim, visando ao aproveitamento de ingredientes, cada vez mais usados em alimentos com alegação funcional, e o aumento no consumo de barras cereais, principalmente, por ser um alimento saudável e prático, esse trabalho teve como objetivo a caracterização microbiológica, fisíco-química de uma formulação de um novo produto: uma barra elaborada com frutas desidratadas e granola, desenvolvida no âmbito de um Edital de inovação em parceria com uma indústria goiana, como uma alternativa para indivíduos com algum tipo de restrição alimentar, como diabéticos e celíacos ou aqueles que buscam um produto que alie qualidade nutricional e sensorial.

\section{Material e Métodos}

\section{OBTENÇÃO DA AMOSTRA}

As barras de frutas desidratadas com granola foram produzidas em uma indústria de produtos naturais, localizada em Goiânia. Após uma sequência de testes determinados por planejamento experimental, obtevese a formulação final do produto com os seguintes ingredientes: frutas desidratadas (abacaxi, ameixa, banana, maçã) e granola (soja tostada e linhaça).

\section{CARACTERIZAÇÃO MICROBIOLÓGICA}

As análises microbiológicas da barra de frutas foram as seguintes: coliformes termotolerantes, Salmonella, Bacillus cereus, bolores e leveduras. De acordo com os métodos: $\mathrm{n}^{\circ} 7251$ da ISO $^{14} \mathrm{n}^{\circ} 6579$ da ISO $^{17}$ e Downes e Ito $^{10}$, respectivamente. A determinação direta da atividade de água pelo higrômetro Aqualab modelo 3TE (DECAGON, USA), à temperatura de $25^{\circ} \mathrm{C}$ ( 3 repetições).

\section{CARACTERIZAÇÃO FÍSICO-QUÍMICA}

As amostras da barra de frutas com granola foram submetidas a análises físico-químicas para determinação da sua composição centesimal.

A determinação de proteínas foi realizada acordo com o procedimento da $\mathrm{AOAC}^{2}$ método $\mathrm{n}^{\circ} 920.87$ a análise de cinzas foi obtida por aquecimento do produto em temperatura próxima a $(550-570)^{\circ} \mathrm{C}$, de acordo com Instituto Adolfo Lutz (2005), método 018 por ZENEBON e PASCUET ${ }^{28}$ umidade e voláteis por HORWITZ ${ }^{13}$. 
A determinação dos lipídios totais foi realizada de acordo com a técnica descrita pelo Instituto Adolfo Lutz (2005), método $\mathrm{n}^{\circ}$ 034B (ZENEBON e PASCUET ${ }^{28}$. Os micronutrientes (Cálcio, Cobre, Ferro, Fósforo, Magnésio, Manganês, Potássio, Sódio, Zinco) foram analisados conforme os métodos $\mathrm{n}^{\circ} 985.35$ e 984.27 da $\mathrm{AOAC}^{2}$ e o selênio por OLSON ${ }^{18}$.

A fibra alimentar total foi determinada pelo método 985.29 AOAC $^{2}$ e PROSKY ${ }^{20}$ fibra alimentar insolúvel pelo método 991.43, segundo HORWITZ ${ }^{13}$ e PROSKY ${ }^{21}$ e fibra alimentar solúvel pelo método 991.43 conforme PROSKY ${ }^{21}$. Para carboidratos foi realizado o cálculo por diferença: $100-(\mathrm{g} / 100 \mathrm{~g}$ umidade $+\mathrm{g} / 100 \mathrm{~g}$ cinzas $+\mathrm{g} / 100 \mathrm{~g}$ lipídios totais $+\mathrm{g} / 100 \mathrm{~g}$ proteína $+\mathrm{g} / 100 \mathrm{~g}$ de fibra alimentar total). A determinação de açúcares por realizada po cromatografia líquida (HPLC) conforme BURGNE.

As calorias foram determinadas por $\mathrm{PASSMOR}^{19}$. O valor energético por $100 \mathrm{~g}$ do alimento foi determinado multiplicando-se as quantidades encontradas de carboidratos disponíveis, proteínas e lipídeos por 4, 4 e 9, respectivamente, e ao final somou-se o resultado das três multiplicações: valor energético $(\mathrm{Kcal})=[(\mathrm{HC} * 4)+(\mathrm{PTN} * 4)+(\mathrm{LIP} * 9)]$

\section{Resultados e Discussão}

A amostra de barra de frutas com granola apresentou atividade de água (aw) de 0,61. Este valor assegura ao produto estabilidade microbiológica, pois de acordo com $\mathrm{Scott}^{24}$ produtos alimentícios com aw $<0,6$ são microbiologicamente estáveis.

Na Tabela 1, estão apresentados os resultados da caracterização microbiológica.

Tabela 1. Caracterização microbiológica de amostra de barra de frutas com granola

\begin{tabular}{|l|l|}
\hline Determinação & Resultado \\
\hline Salmonella (em $25 \mathrm{~g})$ & Ausente \\
\hline Coliformes termotolerantes (NMP/g) & $<3$ \\
\hline Bacillus cereus (UFC/g) & $10^{2}$ (est) a \\
\hline Contagem de bolores e leveduras (UFC/g) & 10 (est) a \\
\hline Atividade de água a $25^{\circ} \mathrm{C}$ & 0,613 \\
\hline
\end{tabular}

$\mathrm{NMP}=$ Número mais provável. UFC $=$ Unidades formadoras de colônias. a Contagem estimada, abaixo do limite de quantificação do método.
Os resultados das análises microbiológicas indicaram que a amostra estava dentro dos padrões estabelecidos pela Resolução RDC n ${ }^{0} 12$ de 02 de janeiro de 2001, da Agência Nacional de Vigilância Sanitária (ANVISA), Grupo de Alimentos ${ }^{10}$, Item $\mathrm{m}$.

Os resultados da caracterização físico-química da barra de frutas com granola confirmaram que o produto desenvolvido possui qualidade nutricional, superior aos produtos do mesmo nicho, como as barras de cereais disponíveis no mercado, conforme apresentado na Tabela 2.

Tabela 2 - Caracterização físico-química de amostra barra de frutas com granola

\begin{tabular}{|c|c|c|c|}
\hline Determinação & \multicolumn{3}{|c|}{ Resultado } \\
\hline & $/ 100 \mathrm{~g}$ & $/ 25 \mathrm{~g}$ & $\% \mathrm{VD}$ \\
\hline Umidade e voláteis $(\mathrm{g})$ & $14,8(0,0) \mathrm{a}$ & 3,7 & - \\
\hline Cinzas $(\mathrm{g})$ & $2,1(0,01) \mathrm{a}$ & 0,5 & - \\
\hline Lipídios Totais $(\mathrm{g})$ & $8,0(0,1) \mathrm{a}$ & 2,0 & 4 \\
\hline Proteína $(\mathrm{g})$ & $7,7(0,0) \mathrm{a}$ & 1,9 & 3 \\
\hline Carboidratos $(\mathrm{g})$ & $58,1(4,9) \mathrm{b}$ & 14,5 & 5 \\
\hline Calorias $(\mathrm{kcal})$ & $335 \mathrm{c}$ & 84 & 4 \\
\hline Frutose $(\mathrm{g} / 100 \mathrm{~g})$ & $17,6(0,2) \mathrm{a}$ & 4,4 & - \\
\hline Glicose $(\mathrm{g} / 100 \mathrm{~g})$ & $14,9(0,0) \mathrm{a}$ & 3,7 & - \\
\hline Sacarose $(\mathrm{g} / 100 \mathrm{~g})$ & $12,1(0,2) \mathrm{a}$ & 3,0 & - \\
\hline Fibra alimentar total $(\mathrm{g})$ & $9,31(0,11) \mathrm{a}$ & 2,33 & 9 \\
\hline Fibra alimentar solúvel $(\mathrm{g})$ & $2,30(0,09) \mathrm{a}$ & 0,58 & - \\
\hline Fibra alimentar insolúvel $(\mathrm{g})$ & $7,01(0,19) \mathrm{a}$ & 1,75 & - \\
\hline
\end{tabular}

a - Média e estimativa de desvio padrão.

b - Calculado por diferença: 100 - $(\mathrm{g} / 100 \mathrm{~g}$ umidade $+\mathrm{g} / 100 \mathrm{~g}$ cinzas $+\mathrm{g} / 100 \mathrm{~g}$ lipídios totais $+\mathrm{g} / 100 \mathrm{~g}$ proteína $+\mathrm{g} / 100 \mathrm{~g}$ de fibra alimentar total).

c - O valor calórico da amostra foi calculado pela soma das porcentagens de proteína e carboidratos multiplicados pelo fator $4(\mathrm{Kcal} / \mathrm{g})$ somado ao teor de lipídios totais multiplicado pelo fator $9(\mathrm{Kcal} / \mathrm{g})$.

De acordo com Figuerola et al. ${ }^{11}$, a relação recomendada de fibras solúveis e insolúveis para uma boa dieta é de 1:2. Com base apenas nessa relação, a aplicabilidade dietética da formulação da barra de frutas com granola é maior que a maior parte das barras disponíveis no mercado. A barra foi classificada como fonte de fibras alimentares, de acordo com a 
legislação brasileira que exige um mínimo de $2,5 \mathrm{~g}$ de fibras/porção para tal classificação. A barra de frutas apresentou um teor de fibras alimentares $40 \%$ superior aos valores reportados por Brito et $\mathrm{al}^{7}$ para barras de cereais comerciais e em relação aos valores de barras de frutas elaboradas com cascas, apresentados por Brito et $\mathrm{al}^{8}$, cerca de $200 \%$ superior.

A amostra também apresentou elevado conteúdo de minerais importantes como fósforo $(\mathrm{P})$, com teores compatíveis aos encontrados em alimentos ricos em fósforo, como feijão $(0,471 \mathrm{~g} / 100 \mathrm{~g})$ e gema de ovo $(0,5$ $\mathrm{g} / 100 \mathrm{~g})$. Destacaram-se também os micronutrientes Manganês (Mn), Magnésio ( $\mathrm{Mg}$ ) e zinco ( $\mathrm{Zn})$, com teores consideráveis de manganês (30\% IDR) e teor de magnésio semelhante ao encontrado em alimentos como quinoa $(118 \mathrm{mg} / 100 \mathrm{~g})$ e soja $(86 \mathrm{mg} / 100 \mathrm{~g})$.

A barra de frutas desidratadas não teve adição de açúcar na sua formulação, sendo esse um diferencial estratégico para posicionamento desse novo produto no mercado. No entanto, para utilização da alegação “ sem adição de açúcar" nos dizeres de rotulagem, fazse necessário o detalhamento dos tipos de açúcares presentes na amostra para identificação na informação nutricional, conforme exigido pela legislação. Por tal motivo, na caracterização físico-química da amostra, as análises de frutose, glicose e sacarose foram realizadas por Cromatografia Líquida.

\section{Conclusão}

A formulação de uma barra elaborada com $80 \%$ de frutas desidratadas gerou um produto com considerável teor de proteínas, micronutrientes, sendo classificado como fonte de fibras alimentares, pela legislação brasileira, trata-se de uma alternativa para consumidores de alimentos saudáveis e/ou funcionais. Pelos resultados obtidos a partir da caracterização microbiológica e físico-química, verificou-se que o produto apresenta boa estabilidade e quando comparado com as barras existentes no mercado, na maior parte, a base de cereais, constatouse a qualidade nutricional e também a funcionalidade conseguida por meio de fibras das frutas e a adição de outros ingredientes com aporte nutricional, como a soja e a linhaça, caracterizando tal produto de consumo rápido como um alimento de alta qualidade nutricional, além de contribuir com o consumo de frutas.
A barra de frutas desidratadas com granola representa uma alternativa para indivíduos com intolerância ao glúten, diabéticos e consumidores que buscam um produto diferenciado por sua qualidade sensorial e nutricional. Esse produto está associado à uma tendência mundial, que são os produtos com foco em saudabilidade, representando também uma oportunidade de mercado para a empresa.

\section{Referências}

1. AOAC-Association Of Official Analytical Chemists. Official methods of analysis. 15th ed. Arlington: AOAC; 1990. 1298p.

2. AOAC Official Method 2003.09 (Salmonella PCR Bax System). In: HORWITZ, W. (ed.), Official Methods of Analysis of AOAC International, 18th ed. Gaithersburg, Maryland: AOAC International, 2005. Chapter 17, p.194.

3. Barbosa, M. Na onda da barra. Com uma gestão alternativa e um produto campeão de vendas, $\mathrm{Nu} \neg$ trimental afasta a crise e volta a ser uma empresa saudável. Disponível em: http://www.terra.com. br/istoedinheiro. Acesso em: 16 mai. 2016

4. Boustani, P.; Mitchell, V.W. Cereal bars: a per $\neg$ ceptual, chemical and sensory analysis. British Food Journal, v. 92, n. 5, p. 17-22, 1990.

5. Brasil, Ministério da Saúde, Agência Nacional de Vigilância Sanitária. Portaria n ${ }^{\circ} 27$, de 13 de janeiro de 1998. Aprova o Regulamento Técnico referente à Informação Nutricional Complementar (declarações relacionadas ao conteúdo de nutrientes). Diário Oficial da República Federativa do Brasil. Disponível em $<$ http://e-legis.bvs.br/leisref/public/showAct. php?id=97> Acesso em: 10 abr. 2016.

6. Brasil, Ministério Da Saúde. Secretaria de Atenção à Saúde. Coordenação-Geral da Política de Alimentação e Nutrição. Guia alimentar para a população brasileira: promovendo a alimentação saudável. Brasília: Ministério da Saúde, 2005.

7. Brito, I.P; Campos; J. M.; Souza, T. F. L.; Wakiyama, C.; Azeredo, G.A. Elaboração e avaliação global de barra de cereais caseira. B. CEPPA, Curitiba, v. 22, n. 1, p. 35-50, 2004.

8. Brito, M. M. De; Sousa, A. L. O.; Lima, R. S. V.; Lima, L. S. L.; Farias, V. L. De; Barbosa, M. C. F.; Elaboração e avaliação centesimal de barras de frutas desidratadas com adição de cascas, p. 4744-4751 . In: Anais do XX Congresso Brasileiro de Engenharia Química - COBEQ 2014 [= Blucher Chemical Engineering Proceedings, v.1, n.2]. São Paulo: Blucher, 2015.

9. Burgner, E.; Feinberg, M. Determination of mono - and disaccharides in foods by interlaboratory study: Quantitation of Bias components for liquid chromatography. Journal of AOAC International, v. 75, n. 3, p. 443-464,1992.

10. Downes, F. P. \& Ito, K. (eds.). Compendium of Methods for the Microbiological Examination of Foods, 4th ed. Washington: 
American Public Health Association, 2001. 676 p.

11. Figuerola, F. et al. Fibre concentrates from apple pomace and citrus peel as pontential fi bres sources for food enrichment. Food Chem., v. 91, n. 3, p. 395-401, 2005.

12. Freitas, D. G.C.; Moretti, R. H. Caracterização e avaliação sensorial de barra de cereais funcional de alto teor protéico e vitamínico. Ciência e Tecnologia de Alimentos, v. 26, n. 2, p. 318324, abr-jun., 2006

13. Horwitz, W. (Ed.). Official methods of analysis of the Association of Official Analytical Chemists. 18th ed.Gaithersburg, Maryland: AOAC, 2005. Current Through Revision 1, 2006. cap. 32, met. 920.87, p. 14.

14. ISO 7251. Microbiology of food and animal stuffs - Horizontal method for the detection and enumeration of presumptive Escherichia coli - most probable number technique, 3rd ed. The International Organization for Standardization, 2005.

15. ISO 6579. Microbiology of food and animal feeding stuffs Horizontal method for the detection of Salmonella spp., 4th ed. The International Organization for Standardization, 2002, Corrigendum 1:2004, Amendment 1:2007.

16. Márquez, L. R. Fibra Terapêutica. Nutrição em Pauta. Nov 2001. Disponível em <http://www.nutricaoempauta.com.br/novo/51/ entrevista1.html $>$ Acesso em 09 maio 2016.

17. Matsuura, F. C. A. U. Estudo do albedo de maracujá e de seu aproveitamento em barra de cereais. Tese de doutorado, UNICAMP, Campinas, SP, Brasil, 2005.

18. Olson, O.E.; Palmer, I.S.; Cary, Eke. Modification of the official fluorimetric method for selenium in plants. Journal of the Association of Official Analytical Chemists, Washington, DC, v. 58, n.1, p. 117-121, 1975.

19. Passmore, R.; Nicol, B.M.; Rao, M.N. Manual Sobre Necessidades Nutricionales Del Hombre. Ginebre: O.M.S., 1975. (Série de Monografia, 61). United States Department Of Agriculture. Composition of Foods. Agriculture Handbook $\mathrm{N}^{\circ} 8$, WASHINGTON; USDA, 1963.

20. Prosky, L.; Asp, N-G; Furda, I.; Devries, J.W.; Schweizer, T.F. \& Harland, B.F. Determination of total dietary fiber in foods, food products and total diets: Interlaboratorial Study. Journal of The Association Official Analytical Chemists, Arlingtton, v.67, n.6, p.1044-1052, 1984.

21. Prosky, L.; Asp, N-G.; Schweizer, T.F.; Devries, J. W.; Furda, I. Determination of insoluble and soluble dietary fibers in foods and food products. Journal of the Association of Official Analytical Chemists International, v.75, n.2; p.360-367, 1992.

22. Rosa, V.; Granada, G. G.; Zambiazi, R. C.; Caracterização física e química de granolas. In: $9^{\circ}$ Congresso DE Iniciação Ciêntifica $/ 2^{\circ}$ Encontro Da Pós Graduação - UFPEL, FURG, UCPEL, Pelotas - RS, 2000. Resumos ...: Pelotas - RS, v. 2, p. 715.

23. Saura-Calixto, F. Fibra dietética de manzana; hacia nuevos tipos de fibras de alta calidad. Alimentaria. v. 5, p. 57-61, 1993.
24. Scott, W. J. Water relations of food spoilage microorganisms. Adv. Food Res., v. 7, n. 9, p. 83-127, 1957.

25. Tettweiler, P. Snack Foods Worldwide. Food Tech. v. 45, p. 58-62, 1991.

26. Tungland, B. C.; Meyer, D. Nondigestible Oligo- and Polysaccharides (Dietary Fiber): Their Physiology and Role in Human Health and Food. Comprehensive Reviews In Food Science And Food Safety. v. 1, p. 73-77, 2002.

27. Zenebon, Odair; Pascuet, Neus Sadocco (Coord.). Métodos físicoquímicos para análise de alimentos. 4 ed. Brasília: Ministério da Saúde/ANVISA; São Paulo: Instituto Adolfo Lutz, 2005. cap. 4, met. 018, p. 105.

28. Zenebon, Odair; Pascuet, Neus Sadocco (Coord.). Métodos físicoquímicos para análise de alimentos. 4 ed.Brasília: Ministério da Saúde/ANVISA; São Paulo: Instituto Adolfo Lutz, 2005. cap. 4, met. 034B, p. 11.

\section{Karolline F. Siqueira* \& Christiane A. Starling}

Instituto SENAI de Tecnologia em Alimentos e Bebidas- Rua Professor Lázaro Costa n 348, Vila Canaã, CEP: 74415-420, Goiânia, Goiás, Brasil.

*E-mail: karollinefs@gmail.com 